\title{
Ein mittelalterliches Operationsset
}

\section{Iris Ritzmann}

Prof. Dr. med. et lic. phil., Mitglied der Redaktion Medizingeschichte

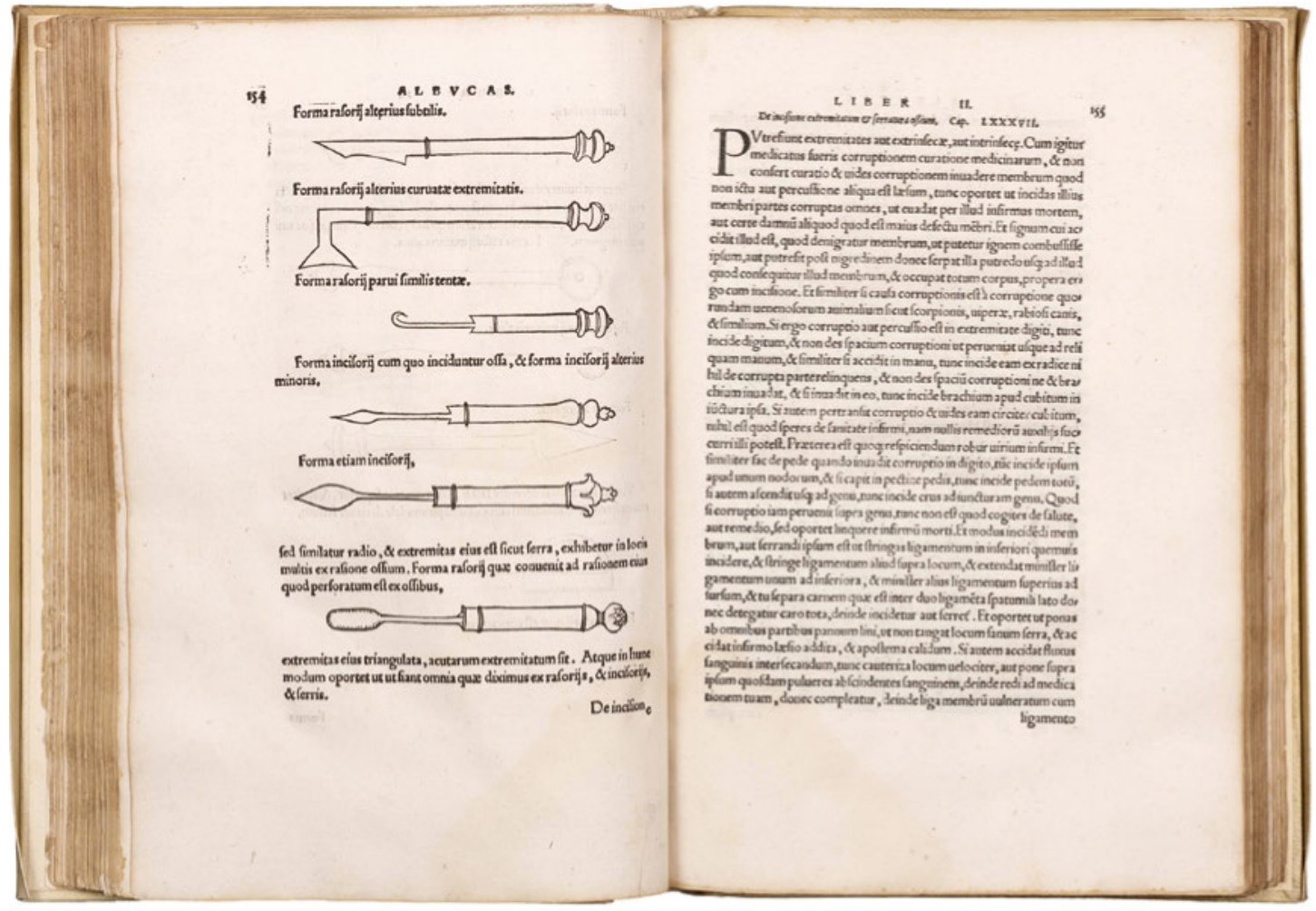

Chirurgische Instrumente in "Albucasis» (Abulcasis): Methodus Medendi certa, clara et brevis, Basel 1541, S. 154 (Sammlung Dr. Franz Käppeli)

Für jeden Eingriff soll der Chirurg das richtige Werkzeug einsetzen, fordert Abulcasis. Seine mittelalterlichen Handschriften beinhalten detaillierte Zeichnungen fein ziselierter Zangen und Messer, Schaber und Klemmen, die in der vorliegenden Ausgabe erstmals mit abgezeichnet und gedruckt wurden. Auf den Holzschnitten sind verschiedenartig gebogene Schnittmesser oder "Rasorii» zu sehen, die sowohl für operative Eingriffe als auch kosmetisch Verwendung fanden. Weiter unten folgen die Stichinstrumente oder «Incisorii» in unterschiedlichen Grössen. Und schliesslich ist auch ein Knochenschaber erkennbar. Die kurzen Beschreibungen lassen erahnen, welche Leiden damals durchgestanden wurden.

Was weiss man über den Autor? Oben an der Seite steht der Autorenname "Albucas.» Ist bei diesem frühen Druck mit beweglichen Lettern versehentlich der Buchstabe «L» verrutscht? Abulcasis wirkte in der Zeit um das Jahr 1000 als Leibarzt des Kalifen von Córdoba. Im Lauf der Jahrhunderte erlebte sein arabischer Name «Abu l-Qasim» verschiedene Schreibweisen und Ver- ballhornungen. Das Werk mit dem Titel «Methodus Medendi certa, clara et brevis», also "Sichere, verständliche und kurze medizinische Behandlungsweise», erschien daher 1541 wirklich unter dem Autorennamen «Albucasis» in Basel.

Das erste Kapitel widmet sich der Behandlung mit dem Glüheisen, das zweite speziellen Eingriffen wie Steinoperationen, Amputationen, Zahneingriffen, Wundtherapien, das dritte der Behandlung von Frakturen und Luxationen. Abulcasis ist zwar überzeugt, dass der Arzt nur durch lange Erfahrung und ein breites Wissen die täglich neuen Herausforderungen meistern könne. Sein Hauptinteresse gilt aber den Instrumenten, mit denen er seine Schrift bestückt. Ob die Chirurgen Abulcasis' Anweisungen befolgten, lässt sich nicht nachweisen. Zumindest aber blieben seine Instrumentenbilder durch viele Jahrhunderte hindurch und bis weit in die Zeit des Buchdrucks hinein ein Highlight in jedem grossen Chirurgiebuch.

Bildnachweis

Museum für medizinhistorische Bücher Muri (mmbm.ch) 